\title{
Tosferina: una enfermedad reemergente que merece atención
}

Pertussis: a reemerging disease that deserves attention

La tosferina es un enfermedad infectocontagiosa causada por un tipo de bacteria llamada Bordetella pertussis, la cual puede ser grave y letal si no se trata a tiempo. La mayoría de los casos fatales ocurren en pacientes menores de un año de edad y el $90 \%$ se produce en menores de seis meses, siendo ésta la gran población en riesgo para desarrollar tosferina maligna.

La introducción de la vacuna en la década de los cincuenta y sesenta disminuyó de manera importante la morbilidad y mortalidad de la enfermedad en la población infantil en países industrializados. Sin embargo, a pesar de la extensión de la vacunación, se ha visto un incremento de su incidencia en las últimas dos décadas. Según la Organización Mundial de la Salud (OMS) existe una alta carga de tosferina en los países en desarrollo, convirtiéndola en una de las principales causas de muertes prevenibles por vacunas en el mundo. Así mismo, la OMS estima una ocurrencia de cincuenta millones de casos y 300.000 fallecimientos anuales, con una letalidad del $4 \%$ en los países en desarrollo.

Por su parte, Colombia no está exenta de este mismo contexto ya que, aunque a partir de 1993 la cobertura de la vacunación con DPT aumentó en un 53\% y en los últimos cinco años se ha mantenido en un $80 \%$, en los últimos reportes del año 2011-2012 se evidencian nuevos brotes de tosferina atípicos en grupos poblacionales diferentes a los menores de un año, lo cual enciende una alerta en todos los actores de la gestión de política en salud de nuestro país que propenda en una mejor vigilancia, la ampliación de la cobertura a otros grupos poblacionales y el diagnóstico de la enfermedad.

Precisamente, la reemergencia de la tosferina se enmarca en una dualidad, en primera instancia relacionada con los avances en las técnicas de biología molecular para la identificación de Bordetella pertussis, el mayor reconocimiento de la enfermedad por parte del personal médico, la sospecha clínica en adultos y la mejor vigilancia del evento, lo cual contrasta enormemente con las coberturas inadecuadas de vacunación, la baja eficacia de la vacuna, la ausencia de refuerzos en la población adolescente y adulta, los cambios genéticos del agente causal, entre otros.

En este contexto, la alta cobertura de inmunización con una vacuna eficaz es el pilar de la prevención. La razón de ser de la vigilancia de la tosferina es mo- 
nitorear el impacto del sistema de inmunización, identificar las áreas de alto riesgo y detectar brotes (que deben ser investigados). En los países donde la cobertura es moderada a baja, la vigilancia debe simplemente monitorizar la mejora de la cobertura y la disminución de la incidencia de la enfermedad. Una vez que la cobertura de vacunación es alta y la incidencia de tosferina es baja, la vigilancia debe ser mejorada para comprender la evolución de la epidemiología de la enfermedad y, por lo tanto, orientar la política de vacunación. Estas estrategias podrán tener un impacto muy positivo en la reducción de la carga de la enfermedad en la población infantil, garantizando el avance de nuestros países si se tiene en cuenta que, según el Fondo de las Naciones Unidas para la Infancia (UNICEF), la tasa de mortalidad infantil en menores de cinco años es un indicador que no sólo refleja el nivel y los cambios del estado de bienestar de la infancia, sino también el grado de progreso económico y desarrollo humano de un país.

\section{Tsaura Plor Sánchez}

\section{Isaura Pilar Sánchez, Biol., PhD.}

Docente-Investigador

Grupo de Investigaciones Biomédicas UniRemington

Corporación Universitaria Remington

Medellín, Colombia, junio 2016 